\title{
A diagnostic and therapeutic approach towards the Brugada syndrome - Bosnian and Herzegovinian experience
}

\section{-Edin Begić*, DEnisa Hodžić, (DZijo Begić}

General Hospital "Prim.dr. Abdulah Nakaš", Sarajevo, Bosnia and Herzegovina

RECEIVED:

October 22, 2018

ACCEPTED:

November 5, 2018

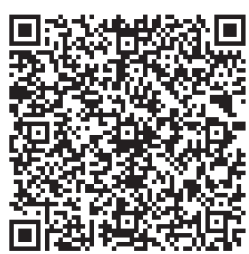

$\square$ Cardiologia Croatica 2018;13(11-12):320.
KEYWORDS: arrhythmia, Brugada syndrome, treatment.

CITATION: Cardiol Croat. 2018;13(11-12):320. | https://doi.org/10.15836/ccar2018.320

*ADDRESS FOR CORRESPONDENCE: Edin Begić, General Hospital “Prim.dr. Abdulah Nakaš”, Kranjčevićeva 12, BA71000 Sarajevo, Bosnia and Herzegovina. / Phone: +387-61-303375 / E-mail: edinbegic90@gmail.com

ORCID: Edin Begić, http://orcid.org/0000-0001-6842-262X • Enisa Hodžić, http://orcid.org/0000-0002-7436-7708 Zijo Begić, http://orcid.org/0000-0002-1863-5755

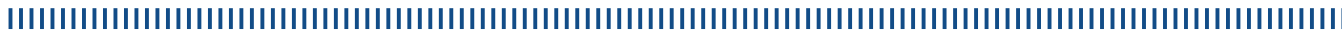

Introduction: Brugada syndrome (BS) is a dominantly inherited arrhythmogenic disease caused by a mutation in the SCN5A gene. It accounts for $20 \%$ of cases of sudden death, without structural heart abnormalities ${ }^{1}$. Diagnosing the BS is achievable by electrocardiography (ECG), ST segment elevation in V1 to V3, with the right bundle branch block pattern as a hallmark of the syndrome ${ }^{2}$. BS is divided into three types. However, only type 1 can be verified with an ECG ${ }^{2,3}$. BS manifests as a syncope that is caused by ventricular tachycardia, which, if converted to ventricular fibrillation, leads to a fatal outcome. An implantable cardioverter defibrilator (ICD) implantation is indicated, while pharmacological therapy on its own is not sufficiently effective. Aim: To present a diagnostic and therapeutic approach towards suspected BS in a younger patient.

Case report: 24-years-old patient was admitted to a hospital, after a cardiac arrest and a prolonged cardiopulmonary resuscitation with intubation. ECG findings verified sinus rhythm, with heart rate of 94 beats per minute, normal heart axis with $\mathrm{PQ}$ interval of $0.16 \mathrm{~s}$, and right bundle branch block (RBBB) with an ST elevation from V1 to V3. An ajmalin provocation test was performed, and ECG changes (J-wave elevation of $>2 \mathrm{~mm}$ with ST elevation from V1 to V3 with RBBB) were recorded, but without induced ventricular arrhythmia. Patent foramen ovale was suspicious as a cause, but after transesophageal echocardiography it was excluded. According to electrocardiographic changes, the BS was diagnosed as the cause of malignant ventricular heart rhythm. Genetic testing for Brugada syndrome was not performed and in consultations with the Centre for Electrophysiology in Sarajevo (Bosnia and Herzegovina) and Zadar (Croatia), the implantation of an ICD was indicated, and subsequently performed. The patient was discharged under pharmacological therapy consisting of metoprolol $25 \mathrm{mg}$ twice per day, amiodarone $100 \mathrm{mg}$ per day, with magnesium, and aspirin once per day.

Conclusion: In daily clinical work, in all conditions of syncope occurring in younger patients, in order to prevent sudden death, an existence of the BS should be considered. An overall clinical status of a patient, including positive ajmaline test with specific ECG changes, can verify BS, even when information on the presence of the SCN5A gene is not available.

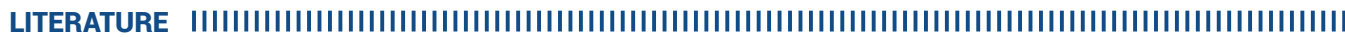

1. Brugada P, Brugada J. Right bundle branch block, persistent ST segment elevation and sudden cardiac death: a distinct clinical and electrocardiographic syndrome. A multicenter report. J Am Coll Cardiol. 1992 Nov 15;20(6):1391-6. https://doi.org/10.1016/0735-1097(92)90253-J

2. Brugada J, Brugada P, Brugada R. The syndrome of right bundle branch block ST segment elevation in V1 to V3 and sudden death-the Brugada syndrome. Europace. 1999 Jul;1(3):156-66. https://doi.org/10.1053/eupc.1999.0033

3. Aizawa Y. Brugada Syndrome: Risk Stratification And Management. J Atr Fibrillation. 2016 0ct 31;9(3):1507. https://doi.org/10.4022/jafib.1507 